\title{
Effect of Pattern Shape of Master Medium on Bit Printing Characteristics
}

\author{
M. Onose, R. Kawasaki, Y. Tanaka, Y. Kawada, T. Komine, and R. Sugita \\ Ibaraki University, 4-12-1 Nakanarusawa-cho, Hitachi, Ibaraki 316-8511, Japan
}

In this study, the bit printing characteristics of line and space (L/S), checkerboard, and dot patterns were compared in experiments. The results indicated that the peak-to-peak values of the MFM output of L/S, checkerboard, and dot patterns were almost the same. The optimum printing field for the L/S pattern was the same as that for the checkerboard pattern, whereas the optimum printing field for the dot pattern was lower than those of the $\mathrm{L} / \mathrm{S}$ and checkerboard patterns. This is because the maximum value of the recording field in the dot pattern was larger than those of the L/S and checkerboard patterns.

Key words: magnetic printing, perpendicular magnetic recording media, bit printing, master pattern

\section{マスター媒体のパターン形状がビット転写特性に及ぼす影響}

小野瀬勝・ 川崎龍太・田中康貴・ 川田裕介 - 小峰啓史・杉田龍二

茨城大学工学部, 茨城県日立市中成沢町 4-12-1 ( $316-8511)$

\section{1. はじめに}

ハードディスク $(\mathrm{HD})$ の高記録密度化, 大容量化が進んでおり， サーボ信号の高速, 高精度かつ安価な形成方法が課題となってい る. これらの課題を解決すべく磁気転写法が検討されている 1) 5). 田中らはマスターの形状, 特にパターン形状の違いがビット転 写特性に及ぼす影響をシミュレーションにより明らかにした6)。し かし, 実験による評価はまだ行われていない. 本研究では, マスタ 一媒体のパターン形状の違いがビット転写特性に及ぼす影響を実 験により検討した.

\section{2. 実験方法}

本研究では, ライン状 (L/S), チェッカー状及びドット状のパタ

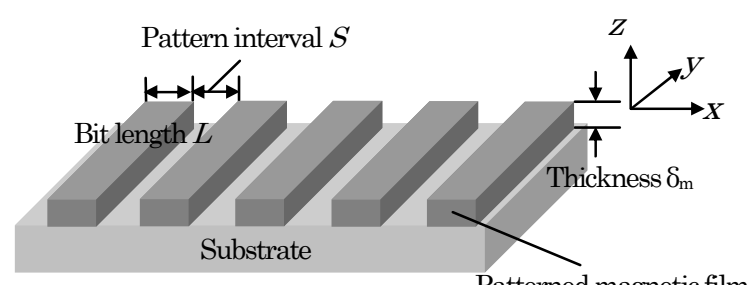

(a) L/S pattern

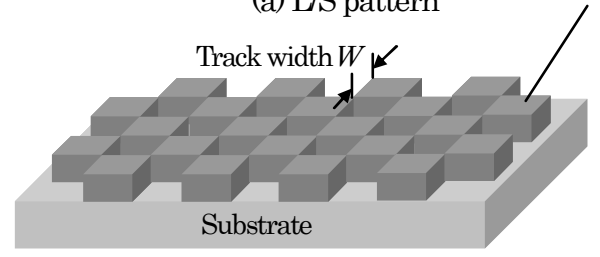

(b) Checkerboard pattern

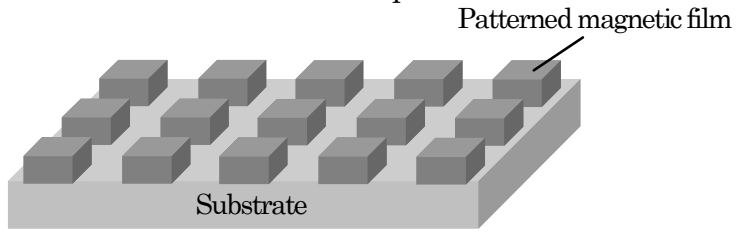

(c) Dot pattern

Fig. 1 Schematic diagram of master media with various patterns: (a) line and space (L/S) pattern, (b) checkerboard pattern, and (c) dot pattern.
ーン形状を有するマスター媒体を用いて, 各々のパターンのビッ 卜転写特性を比較した. 実験に用いたマスター媒体の模式図を Fig. 1 に示寸. マスター媒体は, 基板上に FeCo 膜 (Co 30 at.\%, 飽和磁 化 $\left.M_{\mathrm{s}}=1900 \mathrm{emu} / \mathrm{cm}^{3}\right)$ をライン状, チェッカー状及びドット状 に形成したものを用いた. FeCo の膜厚を $30 \mathrm{~nm}$, ビット長 $L$ を 100 及び $200 \mathrm{~nm}$ とし, チェッカー及びドットのトラック幅 $W$ は, ビット長と等しくした. スレーブ媒体として, 保磁力が約 $4.5 \mathrm{kOe}$ の市販HDを用いた. 転写されたスレーブ媒体の磁化状態は, 磁気 力顕微鏡 (MFM, PNI 社製 Nano R) を用いて評価した. MFM 探 針は, 標準探針 (MFMR) と高分解能探針 (SSS-MFMR) を用い た. いずれも, Si に Co 合金が被膜されている NanoWorld 社製で ある. 標準探針は, Co 合金膜厚が $40 \mathrm{~nm}$, 保磁力 $H_{\mathrm{c}}$ が $300 \mathrm{Oe}$ 及び 探針先端曲率半径が約 $50 \mathrm{~nm}$ である. 高分解能探針は, Co 合金膜 厚が $20 \mathrm{~nm}, H_{\mathrm{c}}$ が $125 \mathrm{Oe}$ 及び探針先端曲率半径が $15 \mathrm{~nm}$ 以下で ある. なお, 探針試料間距離は $10 \mathrm{~nm}$ とした。

ビット転写では, Fig. 2 に示すようにスレーブ媒体の膜面垂直方 向に初期磁化磁場 $H_{i}$ を印加し, 記録層を $H_{\mathrm{i}}$ の向きに初期磁化した 後, スレーブ媒体にマスター媒体を接触させ, $H_{1}$ とは逆向きに転写 磁場 $H_{\mathrm{a}}$ を印加する.

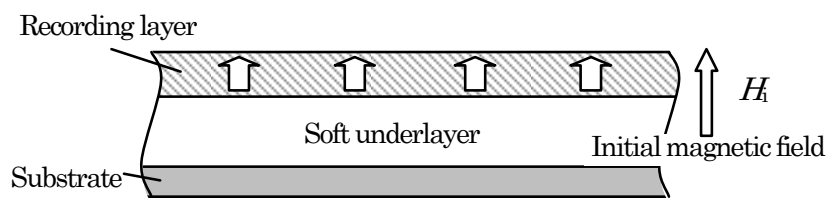

(a) Initial magnetization process

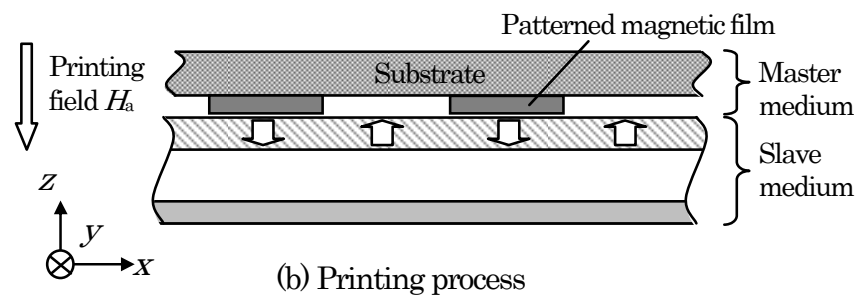

Fig. 2 Schematic diagram of bit printing process. (a) Initial magnetization process. (b) Printing process. 


\section{3. 実験結果}

\section{1 パターン形状の違いがMFM 出カに及ぼす影響}

ビット長 $100 \mathrm{~nm}$ 及び $200 \mathrm{~nm}$ のL/S, チェッカー及びドットパ ターンが転写されたスレーブ媒体の MFM 像及びMFM 出力波形 を, Fig. 3 及びFig. 4 にそれぞれ示す. また, MFM像に対応したマ

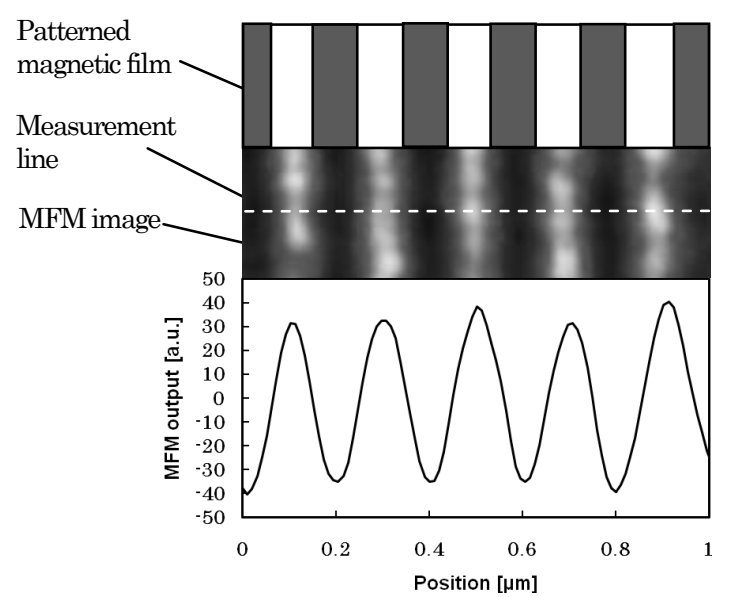

(a) L/S pattern

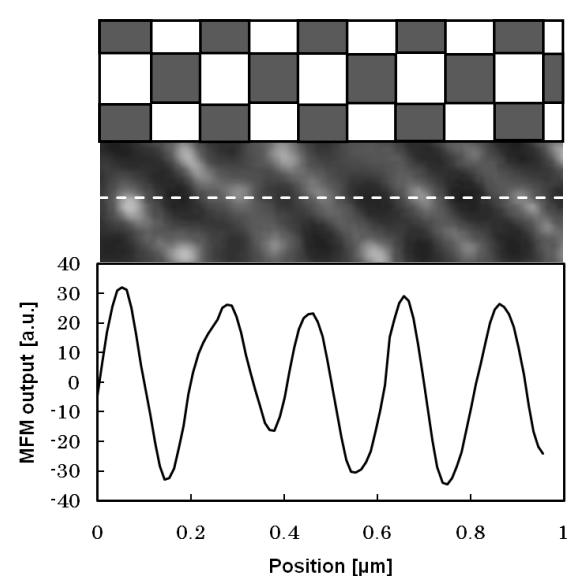

(b) Checkerboard pattern

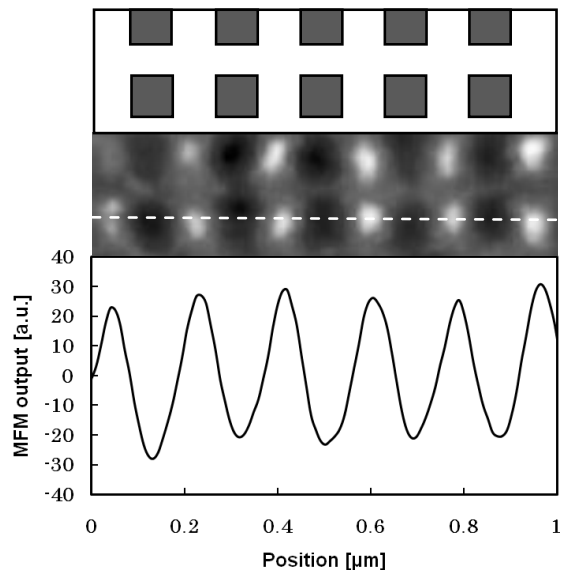

(c) Dot pattern

Fig. 3 Plan view of master media, MFM images and waveform of (a) L/S, (b) checkerboard, and (c) dot patterns in the bit-printed media with bit length of $100 \mathrm{~nm}$.
スター媒体の平面図をFigs. 3, 4 に示寸. なお, MFM探針は標準探 針を用いた. 出力波形はMFM像中の白線部を抽出した. 図中に示 されるマスター媒体の平面図において，グレ一部は磁性膜がある 部分, 白色部は磁生膜がない 部分である. また, MFM 像中におい て, 明部が上向き磁場，暗部が下向き磁場である. スレーブ媒体は 上向きに初期磁化しており，マスター磁性膜接触部で磁化が下向

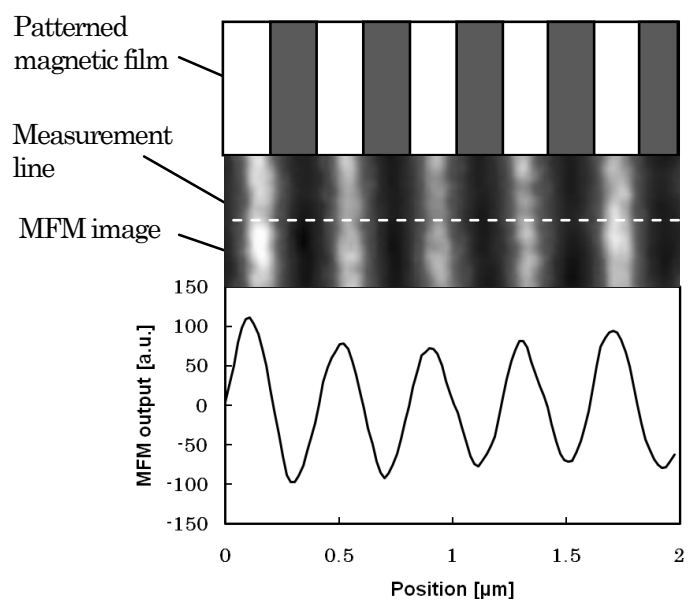

(a) L/S pattern

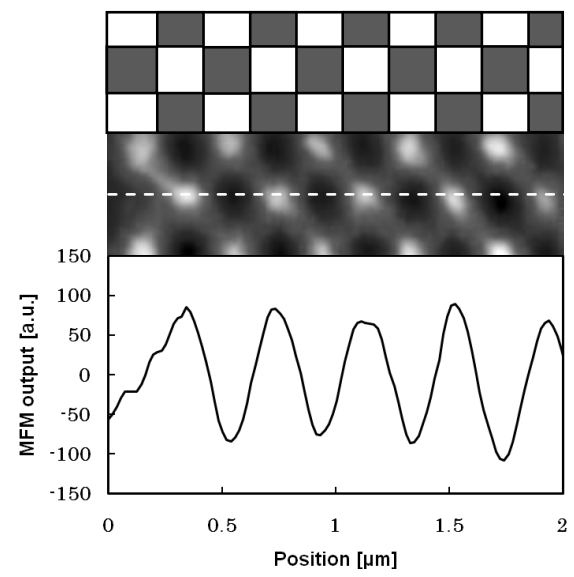

(b) Checkerboard pattern

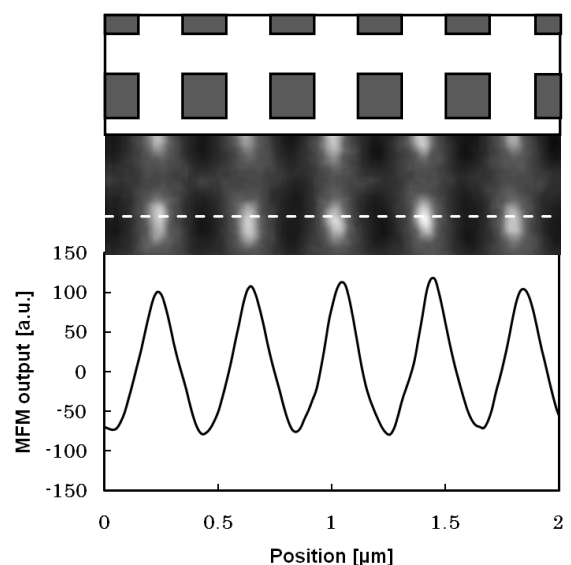

(c) Dot pattern

Fig. 4 Plan view of master media, MFM images and waveform of (a) L/S, (b) checkerboard, and (c) dot patterns in the bit-printed media with bit length of $200 \mathrm{~nm}$. 
きに反転する. すなわち, MFM 像中において, 明部は初期磁化部, 暗部は転写による磁化反転部を示している. L/S 及びチェッカーパ ターンは, ビット長 $100 \mathrm{~nm}$ の場合転写磁場を $4 \mathrm{kOe}$ とし, ビット 長 $200 \mathrm{~nm}$ の場合転写磁場を $5 \mathrm{kOe}$ とした. ドットパターンは, い ずれのビット長においても転写磁場を $3 \mathrm{kOe}$ とした. これらは, 各々のパターンに対して MFM 出力が最大となる転写磁場である (以下，この転写磁場を最適転写磁場と称寸る). Fig. 3及びFig. 4 に 示されるように, ビット長 $100 \mathrm{~nm}$ 及び $200 \mathrm{~nm}$ のいずれのパター ンにおいても, マスターパターン形状を反映した MFM 像が得ら れた. また，いずれの再生波形もほぼ正弦波となっており，マスタ 一磁性膜接触部で下向きに, 非接触部で上向きに磁化されている ことがわかる. Fig. 4 より, ビット長 $200 \mathrm{~nm}$ では, L/S, チェッカ 一及びドットでほぼ同等の出力が得られていることがわかる.こ の結果は, 以前のシミュレーション 6)とも一致している. 一方, ビ ット長が $100 \mathrm{~nm}$ の場合には, Fig. 3 からわかるように, チェッカ 一及びドットに比べて L/S の出力の方が高くなり, 以前のシミュ レーションとは一致していない.

\section{2 転写特性の転写磁場依存性}

ビット長 $100 \mathrm{~nm}$ 及び $200 \mathrm{~nm}$ のL/S, チェッカー及びドットパ ターンにおける MFM 出力の転写磁場依存性を Fig. 5 に示寸. い ずれのビット長でも，ドットの最適転写磁場は L/S 及びチェッカ 一に比べて低くなっていることがわかる.この原因は，ドットパタ ーンを用いた場合に記録層に印加される磁場の最大值が L/S 及び

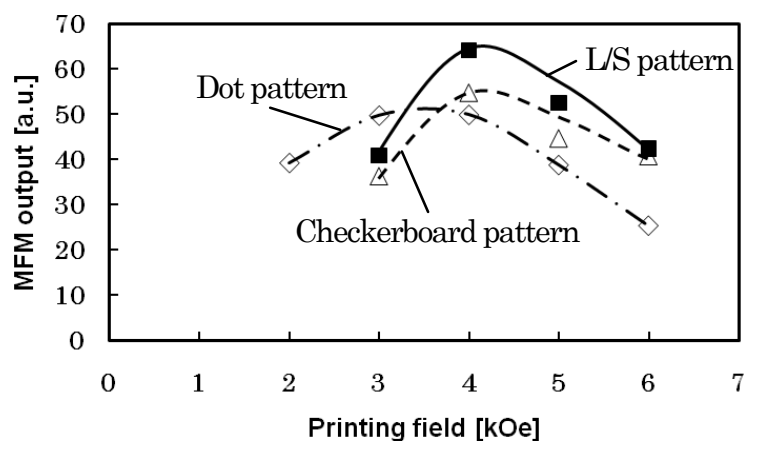

(a) $100 \mathrm{~nm}$

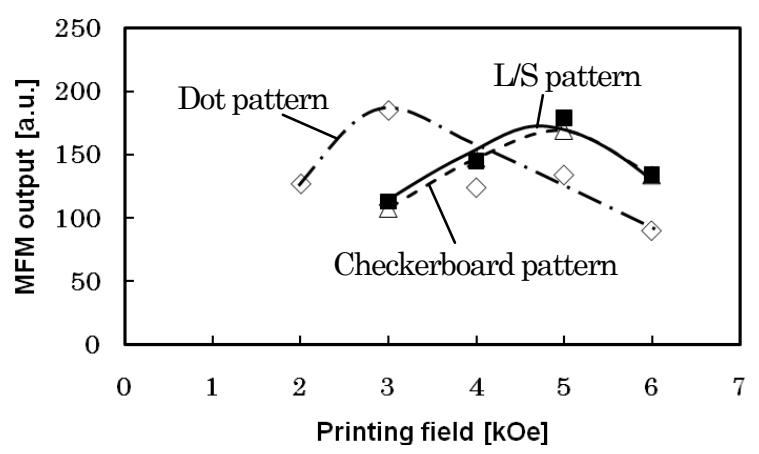

(b) $200 \mathrm{~nm}$

Fig. 5 Printing field dependence of peak-to-peak value of MFM output in the L/S, checkerboard, and dot patterns of bit-printed media with bit lengths of (a) $100 \mathrm{~nm}$ and (b) $200 \mathrm{~nm}$.
チェッカーに比べて大きいためであると推察される ${ }^{6}$. ビット長 $200 \mathrm{~nm}$ のとき, 最適転写磁場における MFM出力がいずれのパタ ーンにおいても同等であるのに対し, ビット長 $100 \mathrm{~nm}$ のとき, 最 適転写磁場における MFM 出力が, L/S に比べてチェッカー及びド ットで低くなっている原因は, MFM 探針先端の曲率半径によるも のと推察される. そこで, 高分解能探針を用いた測定を行ったので, その結果を次節で説明する.

\section{3 高分解能探針を用いた測定及び考察}

3.1 節及び 3.2 節の結果で用いた MFM 標準探針の曲率半径は約 $50 \mathrm{~nm}$ である. ビット長が短い場合, L/S パターンではクロストラ ック方向の隣接ビットはMFM出力に影響を及ぼさない. 一方, チ エッカーやドットパターンではクロストラック方向の隣接ビット からの漏孔磁場が出力を低下させる可能性がある. そこで, 高分解 能探針を用いて, MFM 出力を測定し, 隣接ビットの影響について 検討した. ビット長 $100 \mathrm{~nm}$ のL/S 及びチェッカーにおける MFM 像, MFM 出力波形及びマスター媒体の平面図を Fig. 6 に示す. 出 力波形は MFM 像中の白線部を抽出した. 転写磁場は $4 \mathrm{kOe} と し ~$

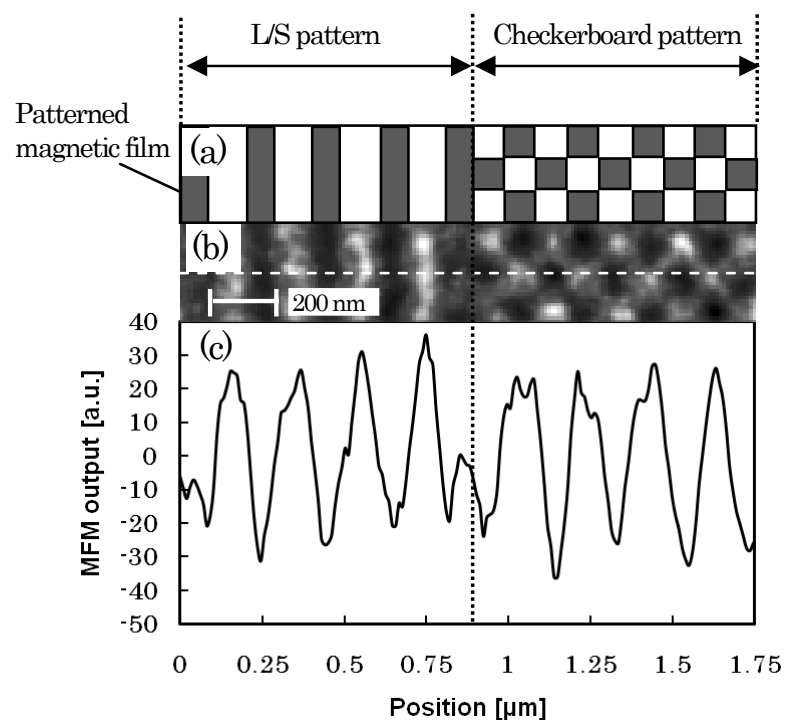

Fig. 6 (a) Plan view of master media. (b) MFM images of L/S and checkerboard patterns of bit-printed media with bit length of $100 \mathrm{~nm}$. (c) MFM output waveform in the L/S and checkerboard patterns.

Table 1 Peak-to-peak values of the MFM output in the L/S and checkerboard patterns of bit-printed media with bit length of $100 \mathrm{~nm}$ obtained by normal and super sharp probes.

\begin{tabular}{|c|c|c|}
\hline \multirow{2}{*}{} & \multicolumn{2}{|c|}{ MFM output [a.u.] } \\
\cline { 2 - 3 } & Normal probe & Super sharp probe \\
\hline L/S pattern & 154 & 49 \\
\hline Checkerboard pattern & 131 & 53 \\
\hline
\end{tabular}


た. 標潐探針及び高分解能探針で測定した場合の L/S とチェッカ 一の平均出力を Table 1 に示す. 標準探針を用いた場合は, チェッ カーに比べて L/S の方が出力が高いが，高分解能探針を用いた場 合, L/S とチェッカーでほぼ同等の出力となっている.これは, MFM 測定時に, 探針の曲率半径の減少に伴い，クロストラック方 向のビット間干渉が起こらなくなったためと推察される. 従って, 前節の MFM 出力の相違はMFM 探針の分解能によるものであり, 転写された磁化強度に相違はなく, ビット長 $100 \mathrm{~nm}$ の場合にお いても, L/S, チェッカー及びドットでほぼ同等の出力が得られる と推察される.これは以前のシミュレーション 6)とも一致してい る.

\section{4. まとめ}

本研究では, マスター媒体のパターン形状の違いがビット転写 特性に及ぼす影響を, 実験により検討した. その結果, 次のことが 明らかになった。

（1）ビッ卜転写されたスレーブ媒体からの再生波形は, L/S, チェ ッカー及びドットパターンともに相違はない．

(2) L/S とチェッカーのビット転写特性はほぼ同等である.

（3）ドットの最適転写磁場は L/S 及びチェッカーに比べて低い.
謝辞 本研究の一部は, 日本学術振興会科学研究費補助金基盤研 究 (B) No.21360159 の支援により行われました. 富士フイルム （株）の皆様にご協力，こ議論を頂きました. 東陽テクニカ（株） 様には MFM 測定に関してご指導を頂きました. ここに深謝致し ます.

\section{References}

1) R. Sugita, T. Kinoshita, O. Saito, T. Muranoi, M. Nishikawa, and M. Nagao: IEEE Trans. Magn., 36, 2285 (2000).

2) R. Sugita, O. Saito, T. Muranoi, M. Nishikawa, and M. Nagao: J. Appl. Phys., 91, 8694 (2002).

3) A. Saito, T. Hamada, T. Ishida, Y. Takano, and E. Yonezawa: IEEE Trans. Magn., 38, 2195 (2002).

4) A. Saito, T. Ono, and S. Takenoiri: IEEE Trans. Magn., 39, 2234 (2003).

5) M. Nishikawa, S. Wakamatsu, K. Ichikawa, T. Usa, M. Nagao, T. Ishioka, T. Yasunaga, T. Komine, and R. Sugita: IEEE Trans. Magn., 42, 2612 (2006).

6) Y. Tanaka, T. Komine, and R. Sugita: J. Magn. Soc. Jpn., 34, 59 (2010).

2010 年 10 月 20 日受理, 2011 年 03 月 24 日採録 